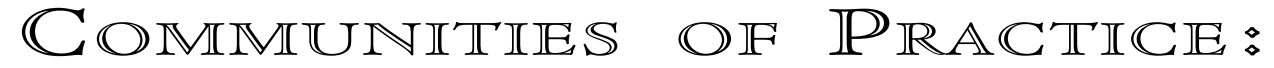

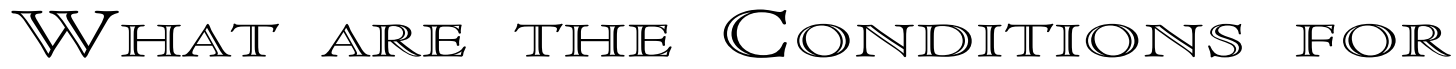

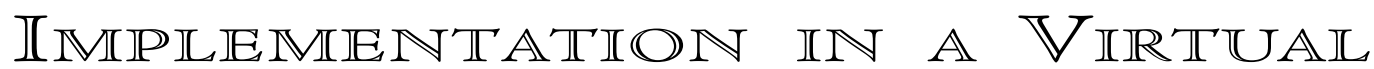

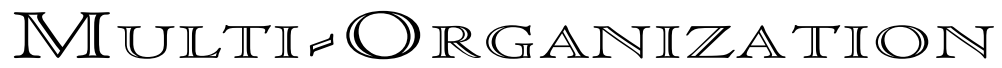 $\mathbb{C} O \mathbb{M} \mathbb{M} \cup \mathbb{N} \mathbb{T} \mathbb{Y}$ ? $*$
}

\author{
Diane-Gabrielle Tremblay**
}

\begin{abstract}
$A B S T R A C T$
ommunites of practice have raised more and more interest over recent years. In this paper, we present a case study of a virtual communitiy of practice (CoP), that is one where participants work from a distance, a situation which has not been studied as often as the communities which work in the same environment. This virtual CoP includes participants from different organizations, and we will determine if the preconditions for implementation are the same as what is documented in the litterature on communities of practice. The research was conducted under the auspices of the CEFRIO (Centre francophone pour l'informatisation des organisations), in 2000-2001. Our data identifies some conditions of success for a virtual multi-organization community of practice, i.e. animation, engagement of participants, and time, something participants lacked here. Most participated quite actively in the community, but some learnt more than they contributed, indicating that there was a certain periphery of participants somewhat less engaged than others. The fact that most do not work with computers and that they had to learn a new software surely explains part of this, although level of participation and motivation was nevertheless quite high. The health sector is under challenge in many countries, Brazil as others, and this case study may be instructive of new ways of developing competencies in the health sector.
\end{abstract}

* This research was conducted under the aegis of the Cefrio (www.cefrio.qc.ca). It was conducted in partnership with colleagues from Université Laval (T.Laferrière), Université de Montréal (M. Campos) and HEC Montréal (C. Bareil, A.Bourhis, L. Dubé, and R.Jacob; see Jacob et al., 2003, for information on the project's participants). The organisational and HRM part of the research was conducted with Anne Bourhis, from HEC Montréal; we wish to thank Mireille Gaudreau, research assistant, for her excellent work on the statistics and Anne Bourhis for her cooperation in the organisational part of the project.

** Prof. Canada Research Chair on the socio-organizational challenges of the Knowledge Economy 


\section{COMIMUNITIES OF PRACTICE}

ommunites of practice have raised more and more interest over recent years. In this paper, we will present a case study of a virtual communitiy of practice (CoP), that is one where participants work from a distance, a situation which has not been studied as often as the communities which work in the same environement. One exception to this is Benoit and Laferrière's case study (2000) and surely, more documentation of cases of virtual CoPs needs to be done. Our case is different from that of Benoit and Laferrière's since participants not only work from a distance, but they also are not employed by the same organization, which increases the challenge of implementation of a CoP. In this paper, we will thus present the case study of a virtual CoP with participants from different organizations, and try to see if the preconditions for implementation are the same as what is documented in the litterature on communities of practice.

We will first present the definition and meaning of the concept of communities of practice (CoP), and recall the elements highlighted by other researchers as conditions of success and for these communities of practice (CoP), based on our litterature review, before we present our case study of a virtual community of practice in the health sector, highlighting data which permit a certain test of conditions of success for a virtual multi-organization community of practice.

First, let us recall that the term « communities of practice » was first used by Wenger and Lave some 13 years ago (Wenger and Lave, 1991). Many different views and definitions have been presented since then, but most, if not all refer to the importance of sharing information within a small group, as well as the value of informal learning for a group and for an organization as a whole. A few definitions of communities of practice which are close to the one we used are presented in Mitchell (2002) :

- communities of practice are groups of people who share a concern, a set of problems, or a passion about a topic, and who deepen their knowledge and expertise in this area by interacting on an ongoing basis (Wenger, McDermott \& Snyder, 2002, p. 4, quoted in Mitchell, 2002 p. 12)

- a group whose members regularly engage in sharing and learning, based on their common interests (Lesser \& stork, 2001, p. 831, quoted in Mitchell, 2002 p. 12)

The main elements stressed here are the sharing of a concern, a set of problems, the ongoing interaction between the group, the ongoing sharing and learning. As we will see later, these elements were found in our community and contributed to its success.

However, as we will see later, the virtual community of practice studied here, is further from some other, maybe more conventional definitions of communities of practice, which refer to a more informal group, whereas the dozen of communities we studied, and the one which is the object of the case study presented here, are structured by an organization and much more formal. Let us nevertheless recall these other definitions, in order to highlight difference in types of communities, which may also raise questions relatively to the conditions of success. Here are a few other definitions:

- $\quad$ groups of people informally bound together by shared expertise and passion for a joint enterprise (Wenger and Snyder, 2000, p. 139);

- informal clusters and networks of employees who work together - sharing knowledge, solving common problems and exchanging insights, stories and frustrations (Lesser \& Prusak, in Lesser et al., 2000, p. 831, quoted in Mitchell, 2002, pp. 11-12).

It must be mentioned that the community we studied was not based on a previously existing informal group, nor was it composed of people who worked in the same workplace, for the same employer, which is rather uncommon in the litterature to this date. However, over recent years, organizations have shown 
interest in workteams that work from a distance, although sharing a project, and it is this that caught our interest for communities of practice working from a distance as well as for different employers.

It must however be stressed that these virtual communities of practice are more than simple teams working from a distance. They are seen as a group that has a common mission, that has a common task and must deliver a product based on the regular exchanges and information sharing within the group, as defined in McDermott (1999). Work teams usuallly have a predetermined goal and schedule, often very clearly defined tasks and their activity is usually centered on their work tasks, and done during working hours; often, work teams disintegrate once the objective is attained, but in the manufacturing sector, they often remain to assume general work tasks collectively (Tremblay and Rolland, 1998). Also, work teams are often characterized by a strong division of labour, whereas communities imply more direct cooperation between the members (Tremblay, Rolland and Davel, 2000). Communities of practice are seen as having wider and less defined objectives, as not having a specific schedule and dates for attaining the various objectives (contrarily to work tasks), and usually go on for quite some time (indeterminate often).

As indicated in much of the litterature on work teams as well as communities of practice, working «together » as a group usually requires some prerequisites, the main precondition appearing to be trust in other members of the group. This is all the more important in a context of communities of practice, since members of the community are expected to share tacit knowledge, to construct collectively new knowledge and possibly new products or services (McDermott, 1999, 2001, Wenger and Snyder, 2000; Adams and Freeman, 2000; Deloitte Research, 2001). It is precisely because of this trust element that many authors recommend that virtual communities of practice be developed on the basis of existing informal groups, groups that share values and already trust each other. This is however often not possible in firms and it is why many virtual communities of practice are designed without being based on a previously existing informal work group, as we will see. This of course represents an additional challenge for CoPs, that is when previous acquaintance and trust of members has to be developed within the CoP, all the more so when it is a virtual CoP.

Amongts the other main prerequisites often mentioned in the Communities of practice litterature (as well as in much of the teamwork litterature - Tremblay, Rolland and Davel, 2000; Tremblay and Rolland, 2000), are the importance of the leader or animator of the community, the interest and motivation of individuals to work together as a group, and the support received from the organization : support and legitimization of the group on the part of the immediate superior or higher levels of hierarchy, financial or non monetary rewards for the participants and the like (Wenger, McDermott \& Snyder, 2002). Available technology and technological support are sometimes mentioned, but most research seems to indicate that the human resources and organizational challenges are more important and that technology plays a more limited role in the success or failure of Communities of practice.

Some elements of the teamwork litterature also appear useful in our consideration of conditions for successful implementation of CoPs and collaboration within them.

According to Letize and Donovan (1990), the leader must proceed through a succession of four functions in order for the team to succeed and in our view, these elements could be transposed to the context of CoPs and organizational learning. At first, he must consolidate the team (leader, trainer and expert roles). He must then, as an animator and facilitator, oversee the development of the skills of the individuals who make up the group. At the next stage, he puts more emphasis on the management of the team's performance (role of auditor and buffer to protect the team from external attacks). Finally, the supervisor plays the role of external consultant to various teams to help them reach their goals (advisor role). 
Roy (1999) identifies three types of supervision that form a kind of continuum of team autonomy. When teamwork is first adopted, the role of supervisor tends to change. The supervisor becomes a facilitator, a resource person or coordinator who helps the team to assume its new responsibilities. A team member may then be chosen as team leader to coordinate and represent the team. He may report to a senior manager or a coordinator who supervises a number of teams. Finally, some firms have chosen to distribute management responsibilities among team members. In this case, each team member so designated becomes the team's reference person for the particular matter for which he is responsible.

Contemporary authors recognize the determining influence of the organizational context on the involvement and effectiveness of teams (Guzzo and Shea, 1992; Sundstrom, De Meuse and Futrell, 1990; Hackman, 1987; Goodman, Ravlin and Argote, 1986; Gladstein, 1984; Nieva, Fleishman and Reick, 1978). Several dimensions of the organizational context are considered - technology, human resource management policy (Shea and Guzzo, 1987a; Hackman, 1987); and the support and involvement of management and the organizational structure (Gladstein, 1984). We have tested many of these dimensions in our analysis of CoPs and the results concerning the animation roles will be presented further on; we will see that they confirm some elements of the teamwork litterature.

Having summarized the essence of the litterature on preconditions for implementation of communities of practice which is pertinent for our purpose here, let us go on to the case study of a Canadian community of practice.

\section{ORGANIZATIONAL LEARNING}

Organizational learning is one of the reasons firms and organizations implement communities of practice. OL can be defined as a collective phenomenon of acquisition and development of knowledge, which transforms the management of situations and situations themselves. The collective dimension of organization can be activated by the circulation and diffusion of new knowledge and by the development of relations between existing competencies.

Duncan et Weiss (1978) define the organization as a group of individuals who engage in coordinated and transform directly or indirectly a series of inputs and outputs. ${ }^{1}$ The organization is thus a system of purposeful actions according to Duncan and Weiss (1978). The organisational efficiency is thus determined by the quality of knowledge available Beyond individual learning, which brings about changes in individuals, organizational learning can translate into changes of another nature, and at another level. In our case study however, the information sharing happens between individuals from different employer organizations, so that the organizational learning can take place in the professional organization, but less at the level of the employer organization, as we will see.

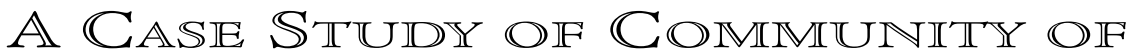

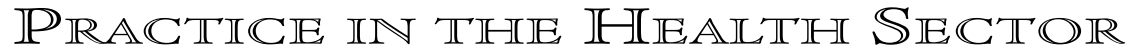

The case study we will present here is one of about a dozen communities that were fostered by the Centre francophone d'informatisation des organisations (CEFRIO), an innovation and transfer research center that supports these communities; the health sector community is the first to be finished and evaluated (although communities should not be considered as «finished》, it is the case here, as we will explain further).

${ }_{1}$ Ducan R. and Weiss A., 1979, Organizational Learning: Implications for Organizational Design, in Research in Organizational Behavior, eds. Staw B.M. and Cummings L.L., Vol. 1, pp75-123. 
The research project initiated by CEFRIO started in 2000 and aimed at the establishment of some 20 Communities. To this day, 10 to 12 communities can be considered active, although many are quite recent (2001-2002), since most took more time to implement than had been planned. This may be due to the fact that the concept was new in many organizations, and also that no informal group existed to receive the community of practice project in many organizations. Thus, the steps leading to implementation took a little more time than seems to be indicated in the litterature, although no definite time frame is mentioned as normal in most case studies.

The objective was to create communities in organizations that wanted to develop such a form of knowledge management, but also to do research on the implementation, conditions of success, impacts of the communities, as well as on interests in participation and levels of satisfaction of participants, amongst other elements. The research was conducted by a team of researchers from four universities, studying different dimensions of the communities (communications, technology, construction of knowledge and organizational-human resources management dimensions, the latter being our own object of analysis). In order for this research to go forward, participant organizations had to accept that the participants respond to some 8 questionnaires, designed to be completed on the web and guaranteeing anonymity to all respondents.

\section{$\mathbb{M I E T H O D O L O G Y}$}

The various participants in the community were not directly observed by researchers, although there were secondary sources of information: information meetings, focus groups which researchers animated and where participants were present, critical incidents documentation by a research assistant, to which researchers had access, and finally and mainly a series of online questionnaires filled by participants. The questionnaires cover the four dimensions mentioned earlier, and for the organizational-HRM dimensions that refers to the following: objective of the organization in setting up a community, as perceived by participants; past work experience and past experiences of cooperation; perception of participants as regards the community experience; objectives attained; satisfaction and general evaluation. There were two questionnaires on organizational and human resources management (HRM) dimensions: one at the beginning and another at the end of the experience, in this case after 6 months of participation. Besides the questionnaires, some focus groups were conducted with animators of the communities and some «critical incidents reports » were drawn up in order to have a better follow-up on all cases.

The case we present here is particularly interesting because contrarily to many communities of practice, the majority of those documented at least, it does not rest on participants from one employer organization, as mentioned previously. It is based on a group of health workers specialized in heart diseases and health, living in different cities accross Canada, that have contacts only through the internet and email. The organization responsible for the project is actually a professional association in the health sector.

With reference to preconditions of success, this is thus an interesting case, since there is no direct management support, little facilitation and no financial incentives offered by the employer directly, as we will see, while these elements are considered essential by much of the litterature (Mitchell, 2002). However, as we will also observe further on, the motivation of participants was very high, and the case is considered a definite success, as data from participants indicate.

Let us add that 21 female health workers participated in this community of practice; we cannot give more details on the specific organization or profession because of confidentiality requirements, but let us say that they are 
all from the same professional category, but different employer organizations and most have been working for over 10 years. Their ojective was to develop a website that was to be filled with information on heart health and heart diseases. In this sense, they had a definite objective and not so much a general perspective of learning as is sometimes the case in communities of practice. This determined the type of exchanges between participants: they mainly exchanged information to be included in the website, opinions and advice on how to present the information on the website, information and opinions on alternative treatment of heart disease and problems. The community was animated by one animator, and she was very active in her work; she is the only person who had time paid to participate in the community, in fact to animate it. The success of this community is partly due to the fact that the animator did not change and was very dynamic, contrary to what happened in other cases. The emails of the animator and participants were generally sent to all, then organized and classified on a special site for information exchange and retrieval. The exchanges were limited to issues to do with the information to be put on the website on heart health and diseases and did therefore not cover issues of more urgency, although this may be considered in future applications. The objective of this first experiment was to develop competencies in collaboration and information sharing, and most feel this has been attained. Although part of these competencies can be transferred into the regular workplace of the participants, the community of practice dealt with an issue outside of work activity of the participants, so there were no questions concerning impact on performance at work after the experience.

Let us now turn to the more detailed analysis of this case and the results we collected through the web survey.

\section{ATTAINMIENT OF OBIECTIVES}

We will first look at the evaluation of the participants concerning the attainment of objectives of the community, then at some of the elements that have been identified as preconditions for the success or failure (i.e. group dynamics and learning).

As concerns the objectives, all those who responded to the questions relative to the objectives agree that these objectives were attained. The main objective of the community was, as mentioned, to create a website which would contain information on heart diseases and heart health. All 21 participants agree that this objective was attained.

However, as various objectives of communities of practice were identified in the litterature on communities (McDermott, 1999, 2000, 2002, Mitchell, 2002, etc.) as well as on teamwork (Tremblay, Rolland and Davel, 2000; Davel et al., 2001) and on collaborative work (Deschênes; Henri and Lundgren, 2000), we wanted to know to what extent these general objectives of communities of practice and of collaborative work or teamwork might have been attained before we go on to explain the conditions which might explain attainment of objectives.

It is interesting to note that the sharing of information and knowledge comes first, followed by the experimentation of a new mode of resolution of problems and a better utilisation of delocalized resources. On a more general note, they also consider that the virtual community project favours excellence, and stimulates creativity and innovation. 


\begin{tabular}{l|c}
\hline Foster innovation (ex : knowledge sharing in order to develop new & $\begin{array}{c}\text { Average } \\
\text { score }\end{array}$ \\
ideas for better products, services, practices, processes)
\end{tabular}

${ }^{1}$ Question : Indicate to what extent, in your opinion, these objectives were attained in your community of practice. Scores are from 1 to 5 , where 5 indicates the objective was fully attained.

Some more detailed data on participation in the community and other elements will help us understand what were the preconditions for these various objectives to be attained. This will permit a test of the general preconditions for CoPs in a virtual context, since most were derived from litterature on non virtual communities of practice, as well as partly from litterature on collaboration (Henri and Lundgren, 2000), and on teamwork (Tremblay, Rolland and Davel, 2000)2.

\section{PARTICIPATION IN $\mathbb{P} \mathbb{H} \mathbb{E}$ $\mathbb{C} O \mathbb{M} \mathbb{M} \cup \mathbb{N} \mathbb{I} Y$ OF $\mathbb{P} \mathbb{R A C T I C E}$}

\section{INDIVIDUAL PARTICIPATION}

The health workers have a very positive view on their participation in the community of practice. We wanted to know whether this participation was beneficial from a personnal or professional point of vie and we wanted to know if they felt they had learned from others and to what extend they had themselves contributed to the community. This is important since litterature on teamwork and group activities often indicates that a few leaders participate in the project (a hardcore of a few participants) while many others remain in the periphery. In 
the case of a virtual community, where participants are not face to face, it is all the more easy to just sit in or read messages, without fully participating in the community. However, participation of a large number is essential to really implement a community of practice and consider it a success. The data does indicate a higher level of learning from the community $(5,24)$ and of professional and personal enrichment $(5,95$ and 6,10$)$, than a level of contribution to the community $(4,29)$. In the focus group, it was mentioned that these health workers do not have computers accessible easily in their work environment, they don't use computers frequently, and the data do indicate that their participation was usually outside of working hours. This made it more difficult for some to participate and feel comfortable in contributing to the group's project. This may explain that a certain number learnt from the experience and exchanges, but may not have contributed as much as could be hoped for or expected. Also, the 6 month limit imposed on this CoP may also explain that some may not have had enough time to really get used to the technology and the group and to feel comfortable in participating. Time constraints may also be important, as we will see further on.

Table 2 - Evaluation of Various Dimensions of Participation

\begin{tabular}{l|c}
\hline & Average (1) \\
\hline I found my participation in the CoP enriching personally & 6,10 \\
I found my participation in the CoP enriching professionally & 5,95 \\
I personally contributed a lot to the CoP & 4,29 \\
I personally learnt a lot from the CoP & 5,24 \\
I am personally very satisfied of my participation in the CoP & 4,57 \\
I would be interested to continue to participate in a CoP & 5,62 \\
\hline
\end{tabular}

${ }^{1}$ Question : What is your global evaluation of your participation in the CoP? Scores from 1 to 7 where 7 indicates that the respondent is totally in agreement with the proposition.

Nevertheless, there is a relatively high level of participation and a high interest in continuing to participate in such a project $(5,62)$, which is interesting, since to our knowledge, there has been no study of virtual communities in professional associations, or at least none documented. Clearly, the participants feel they learnt a lot from the experience on a professional and personal level and this can surely be interesting from the point of view of competence and knowledge development in professional associations or orders, which often seek for new ways of developing competencies within their membership.

DYNAMICS OF THE GROUP

Having worked previously on teamwork (Tremblay and Rolland, 1998, Tremblay, Rolland and Davel, 2000), and having observed in the litterature on teamwork as well as on communities of practice (Mitchell, 2002, Wenger, 1999) that trust is essential in participation in group tasks or activities, it appeared important to evaluate the relations within the group to understand if this dimension is as important in a virtual community and how things play out in such an environment. Respondents indicate that a positive relation and interaction within the group was maintained throughout the project, which lasted 6 months. Information sharing increased, which is important, since it is one of the main objectives, if not the main objective of the communities (Mitchell, 2002, Wenger, 1999, 2000). To a slightly lesser extent, participants indicate that cohesion of the group and complicity also increased over time; since communities do not usually 
have a fixed end, as this group did, this observation is interesting. However, we would probably need a longer time span to evaluate whether the interest might diminish over time and impact negatively on information sharing and cohesion. There is however a small indication of rivalries and tensions developing over time, although the participants majoritarily hold a different view. In work on collaboration and learning (Henri and Lundgren, 2000), there is indication that complicity and group cohesion are essential to learning and collaboration. It is interesting to find these elements confirmed here, all the more so in an environment characterized by distance between participants working on the same project.

Table 3 - Evolution of Group Dynamics

\begin{tabular}{l|c}
\hline & Average (1) \\
\hline Information sharing increased over the months & 5,81 \\
Complicity between participants increased over the months & 5,47 \\
Group cohesion increased over the months & 5,79 \\
Rivalries increased over the months & 2,06 \\
Tension increased over the months & 2,11 \\
\hline 1 Question : What is your global evaluation of your participation in the CoP? Scores from 1 \\
to 7 where 7 indicates that the respondent is totally in agreement with the proposition.
\end{tabular}

As much of the litterature on communities highlights the importance of the role of the leader or animator of the community as a crucial condition for implementation of CoPs, this dimension was also considered in the survey, and we now turn to this.

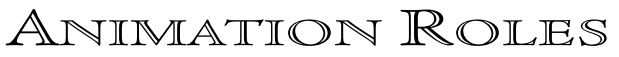

The animation role is all the more important in a virtual community of practice, relying totally on electronic exchanges, and it is surely more challenging in this context as well. In the case studied here, all data and information collected indicates that the role of the animator was crucial. The focus group, the participant observation of one researcher as well as the survey data included here all indicate that the animator was very active and played a crucial role, if not the most crucial role, in the success of the community. While many other factors such as individual motivation and trust of other participants are surely important in this case, the absence of management support and the absence of any form of monetary or other reward in the workplace, make the role of the animator even more crucial.

It was observed that $90 \%$ of participants were « very satisfied » and $10 \%$ satisfied with the animator of this virtual community; also, information gathered in focus groups and various exchanges related to the research confirm that the involvement of this animator was excellent, if not exceptional. It was also observed that many other CoP projects did not go forward or took time to go forward precisely for lack of an active and motivated animator.

Given the importance of the animator or leader of the community, we investigated the roles which appear crucial, based on the litterature on CoPs. The participants were thus questioned as to the roles which they found important amongst the roles identified in the litterature and the roles which were effectively assumed by the animator of the community.

The answers reported in table 4 indicate clearly that the animator was very active (scores are all over 6 out of 7) and was active in many ways, not only concentrating on one or a few of the roles of the animation. She was dynamic, presenting new ideas and tools, leading discussions, supporting individual members, giving expertise on collaboration tools online, measuring progress and informing 
members. To date, we have no survey data to compare this case to others, but focus group exchanges and participant observation of some members of the team indicate that this element is crucial, especially in a virtual community of practice. Indeed, the few communities that are very active and appear successful to date have this characteristic in common : a very dynamic animator, very motivated by the project.

Table 4 - Roles Assumed by the Animator

\begin{tabular}{|c|c|}
\hline & Average $^{(1)}$ \\
\hline Leading and animating discussions on the web & 6,50 \\
\hline $\begin{array}{l}\text { Developing interest of members for the task to be done (ex: } \\
\text { relaunching debates, reminding of group consensus) }\end{array}$ & 6,40 \\
\hline $\begin{array}{l}\text { Being dynamic in order to boost members' participation (ex : } \\
\text { individualized contact, working behind the scene) }\end{array}$ & 6,74 \\
\hline $\begin{array}{l}\text { Individually supporting members of the group when they have } \\
\text { difficulties }\end{array}$ & 6,61 \\
\hline Giving expert advice concerning collaboration tools & 6,35 \\
\hline Measuring progress of task and informing & 6,75 \\
\hline $\begin{array}{l}\text { Boosting continuous participation in the CoP (ex : proposing new } \\
\text { ideas, new tools) }\end{array}$ & 6,70 \\
\hline
\end{tabular}

OR GANIZATIONAL SUPPORT

Management and organizational support are often considered essential to implement and maintain communities of practice (Mitchell, 2002). Our case study in the health sector is interesting in this respect since few cases, if any, were documented on communities which rely on the participation of members from different employer organizations, and even more, members that have no previous knowledge of each other and have to work together from a distance.

This group thus had no organizational or management support from their employer, all the more so since in many cases the employer was not informed of the project. Four out of 21 participants received some supplementary resources : two received financial resources, one received material resources and another was given time off to participate. This is very different from other organizations, where participants often have time in their job planned for participation in the community. Here, on the contrary, management support from the employer organization is clearly limited since these employers are not involved in the project. However, the professional association which supports the project appeared to be very supportive.

As our data indicate, respondents do estimate that organizational support from the Professional Order was sufficient (5,07 out of 7$)$. It is also interesting to note that the interest of the organization seems to have increased over time to some extent (average of 4,36 out of 7 ). 


\begin{tabular}{l|c}
\hline & Average $^{(\mathbf{1})}$ \\
\hline Organizational support was sufficient & 5,07 \\
Organizational support was insufficient & 3,00 \\
Organizational support was too occasional & 3,00 \\
The interest of the organization seems to have diminished over time & 2,58 \\
The interest of the organization seems to have increased over time & 4,36 \\
\hline
\end{tabular}

${ }^{1}$ Question : In order for your CoP to attain its objectives, you consider that... Scores from 1 to 7 where 7 indicates that the respondent totally agrees with the proposition.

Since most of the litterature on communities of practice refers to implementation within one organization, it is often mentioned that incentives or rewards or various forms of recognition can be important to support participation (Mitchell, 2002). This is also the case in teamwork (Tremblay and Rolland, 2000), and this led us to look at how organizations recognized the participation of members of the communities. It is interesting to note that while employers do little in terms of recognition (performance evaluation or promotion or the like), the participation seems to be recognized somewhat by colleagues or peers from the same professional category.

Table 6 - Recognition of Participation

\begin{tabular}{|c|c|}
\hline & Average $^{(1)}$ \\
\hline $\begin{array}{l}\text { My participation in the CoP was recognized in my performance } \\
\text { evaluation }\end{array}$ & 3,00 \\
\hline $\begin{array}{l}\text { My participation in the CoP was recognized in my career progress } \\
\text { (for exemple, promotions) }\end{array}$ & 3,00 \\
\hline $\begin{array}{l}\text { My participation in the CoP was recognized in my competence } \\
\text { evaluation }\end{array}$ & 3,14 \\
\hline $\begin{array}{l}\text { The transfer of my learning experience in the CoP was recognized } \\
\text { by colleagues in the same job category as I }\end{array}$ & 4,92 \\
\hline
\end{tabular}

\section{CONCLUSION}

Let us now present a few elements of conclusion, on the basis of elements from the litterature presented in the first section of the paper and of our observations in the case study.

As mentioned in the first section, we can conclude that our case study is not of the traditional informal group that gets together in a workplace, but rather a group of people « who share a concern, a set of problems, or a passion about a topic, and who deepen their knowledge and expertise in this area by interacting on an ongoing basis » (Wenger, McDermott \& Snyder, 2002, p. 4, quoted in Mitchell, 2002 p. 12). As we saw, most participated in the community quite actively, but some learnt more than they contributed, indicating that there was a certain periphery of participants somewhat less engaged than others. The fact that most 
do not work with computers and that they had to learn a new software surely explains part of this, although level of participation and motivation was nevertheless quite high.

As is indicated in the litterature, the data do show that participants did share a common concern (sharing knowledge on heart diseases and health), they collectively resolved a set of problems (getting the information on the web, etc.). There was quite constant interaction, although more specific data on this was collected by a colleague specialised in communication studies. The data do indicate however that participants feel there was a regular sharing of information and especially learning from one another, since participants feel they contributed less than they learnt in general.

The informality found in many definitions is of course not characteristic of our case study or of the other communities implemented by Cefrio, since this was a voluntary process for creating such communities, generally from scratch, although some communities do rest partly on previons relations or informal groups, but not exclusively on these. We will later try to compare the cases where participants had previous knowledge of each other and those who did not, since this would also be of interest, but cannot be done until participants from other cases complete the evaluation questionnaires.

Although workgroups or teams that work from a distance have been the object of some attention over recent years, these were generally much more loosely related than a community of practice, which shares a common task and participates directly in the same specific task. Some specialists of cooperation and collaboration actually make a distinction between the two concepts in the sense that in one case there is a strong division of labour, which can also apply to international teams working from a distance, while in the other, none of the participants can go ahead without the others, implying a more direct participation in tasks by participants, as should be the case in the community of practice.

Our group did see itself as having a common mission, a common task and it did deliver a product (website on heart issues) after having had quite regular exchanges within the group, as defined in McDermott (1999). In this sense, our community was to a certain extent close to a work team, since these usually have a predetermined goal and schedule, as did our participants. Their tasks were maybe not precisely defined, but the goal was quite clear and the time limit was determined. Another similarity with the usual definition of work teams is the fact that this community did disintegrate once the objective was attained.

Communities of practice are usually seen as having wider and less defined objectives, as not having a specific schedule and dates for attaining the various objectives (contrarily to work tasks), and usually go on for quite some time (indeterminate often); this was not the case here, but it seems that the first community project has led the way to a new CoP project, based on the same community of practice concept, but with different participants. It must be recalled that the participants all worked on the community of practice project outside of their working hours, which may make it difficult to continue on for a long time. This is due to the fact that the participants in this CoP had different employers and the organization supporting the CoP was a professional association which made it difficult if not impossible for members to participate during working hours.

As indicated in much of the litterature on work teams as well as communities of practice, working «together » as a group usually requires some preconditions, the main condition appearing to be trust in other participants. It is precisely because of this trust element that many authors recommend that virtual communities of practice be developed on the basis of existing informal groups, groups that share values and trust each other. Here, the participants did not know each other, but it can be hypothesized from the information on the case study that the sharing of professional values created sufficient trust and motivation for the projetc to go forward very smoothly. 
We observed that members of the CoP shared a very positive view on their participation in the community of practice. We saw that this participation was beneficial from a personnal and professional point of view and they felt they had learned from others although many may have contributed a little less to the community.

Amongst the main preconditions often mentioned in the Communities of practice litterature (as well as in much of the teamwork litterature), are the importance of the leader or animator of the community, the interest and motivation of individuals to work together as a group, and the support received from the organization (Wenger, McDermott \& Snyder, 2002). We saw that there was little support from employers and from the organization which fostered the community, but the animator of the community clearly compensated very largely for the lack of support or recognition in other realms. This seems to indicate that for a virtual multi-organization CoP to develop, the crucial factor may well be the quality and dynamism of animation and leadership, since the individual employers of the participants are less involved, if at all. Also, the professional identity and professional recognition by members of the same professional category have surely played an important motivational role here, since participants indicate that this recognition was higher than that in their employer organization.

Group cohesion and complicity also appear to be important factors, as identified in the litterature on collaborative work (Henri and Lundgren, 2000), while rivalries and tensions seem to have been limited in this CoP, which surely favored a successful implementation.

While group cohesion, complicity and dynamism of the leadership and animation are crucial factors confirmed as essential to successful implementation, and contributed to make a success of this case study, it could be recommended that virtual multi-organization CoPs should pay more attention to recognition and support within the employer environment, even if the employer is not directly involved, since this would be useful for participants and may as well provide benefits to the employer. However, let us recall that while part of the competencies developed here - cooperation and information exchange capacity - can be transferred into the regular workplace of the participants, the participants dealt with an issue outside of their work activity, so it is difficult to conclude anything on the impact on performance at work after the experience.

Considering the importance of the health sector in most countries, and considering the important challenges it has to face in terms of knowledge development and transfer, the concept of communities of practice can surely be an interesting mode of learning for this sector. While our case study looked at a professional association, it seems this mode of cooperation and learning finds strong support with health workers and it could surely be used more directly in the employer organizations, while this was not the direct object of the very novel experiment studied here.

$\mathbb{R} \mathbb{E} \mathbb{E} \mathbb{R} \mathbb{N} \mathbb{C} \mathbb{S}$

ADAMS, Eric , FREEMAN, Christopher, (2000),Communities of practice: bridging technology and knowledge assessment, Journal of knowledge management; volume 4 no. $1 ; 2000$, pp 38-44

BENOIT, Jean, LAFERRIÈRE, Thérèse (2000). Une communauté de pratique en réseau : le forum de discussion et la base de connaissance des inspecteurs de la commission de la santé et de la sécurité du travail (CSST) 1996-1999, Étude de cas soumis au réseau des centres d'excellence en télé-apprentissage du Canada, 27 pages. HTTP://WWW.TACT.FSE.ULAVAL.CCA/FR/HTML/TELECAST/ CPCSST.HTML 
BOURHIS, A. and TREMBLAY, D.-G. (2004). Nouveaux modes de travail et de collaboration à l'ère d'internet : les communautés de pratique virtuelles. Rapport organisationnel. Québec: Cefrio. 140 pages. Disponible sur www.cefrio.qc.ca

DAVEL, E., J.R. Gomez da Silva, Rolland, D. et Tremblay, D.-G.. (2001).

Comunicaçao e competências no trabalho em equipe. Dans Arche interdisciplinar. Vol. 9 no 28. Rio de Janeiro .SBE Universidade Candido Mendes. Pp. 39-59.

DELOITTE Research (2001), Collaborative Knowledge Networks : Driving workforce performance through Web-enabled communities

DESCHÊNES, A.-J. et coll, «Constructivisme et formation à distance », dans

DistanceS, 1(1), 9-26, disponible à HTTP//:CQFD.TELUQ.UQUEBEC.CA/ DESCHENES.PDF

FAERBER, Richard, Apprentissage collaboratif à distance : outils, méthodes, et comportements sociaux, Biennale éducation et formation, en ligne http: WWW.INRP.FRANCESBIENNALE5BIENNALECONTRIBLONGL139.HTM

FOUCHER, Rolland et al. (2000), L'autoformation relié au travail : apports européens/nord-américains pour I'an 2000. Collectif sous la dir. de Rolland Foucher, Éditions Nouvelles, 2000

GUZZO, R. A. ET F. P. SHEA (1992), « Groupe performance and intergroup relations in organizations », dans DUNNETTE, M. D. ET L. M. HOUGHT (Eds), Handbook of Industrial and Organizational Psychology, vol. 3, Palo Alto, Consulting Psychologists Press.

HACKMAN, J. R. (1987), « The design of work teams », dans LORSCH, J. W. (ed.), Handbook of Organizational Behavior, Englewood Cliffs, Prentice-Hall.

HENRI, France et Karin LUNDGREN-CAYROL (2000) L'apprentissage collaboratif : essai de définition, Télé-université, 2000.

HENRIKSSON, Kristina. (2000) When Communities Of Practice Came To Town : On Culture And Contradiction In Emerging Theories Of Organizational Learning, 2000/3, Issn 1103-3010

HILDRETH, Paul; KIMBLE, Chris; WRIGHT, Peter, Communities of practice in the distributed international environment, Journal of Knowledge Management; Volume 4 No. $1 ; 2000$

LEMIRE, Gilles, HARVEY, Pierre-L. (2002) Et si l'autoconstruction des savoirs dans des espaces communautiques était l'une des voies privilégiées par les TIC!, Actes du colloque 2001 bogues : globalisme et pluralisme, Montréal, 24 au 27 avril 2002.

LETIZE, L. ET M. DONOVAN (1992), Un siècle de rationalisation taylorienne : sociologie du travail, représentations et subjectivité, Université de Paris VIII.

MASIE, Elliot, «Knowledge Management - Training's New Umbrella », http:// www.abouthr.com/hrwork.asp?articleno=5\# article

MCDERMOTT, R. (1999). Nurturing Three Dimensional Communities of Practice: How to get the most out of human networks. Knowledge Management Review. Fall Edition.

MCDERMOTT, R. (2000). Knowing in community: Ten Critical success Factors in Building Communities of Practice . at http://www.co-i-l.com/coil/iknowledge

MITCHELL, J. (2002). The potential for communities of practice. Australia : John Mitchell and associates. 102 p.

SHEA, G. P. ET R. A. GUZZO (1987), « Group effectiveness : what really matters? », Sloan Management Review, printemps, p. 25. 
SUNDSTROM, E., DEMEUSE, K. P. ET D. FUTRELL (1990), « Work teams : applications and effectiveness », American Psychologist, n० 45, p. 120-133.

TREMBLAY, D.-G (2004a). Virtual Communities of practice : towards a new mode of Knowledge sharing and learning ? dans R. Ruzicka, J.H. Ballantne et J.A.Ruiz San Roman (2004, eds). Key Contexts for Education and Democracy in Globalising Societies. Prague: Accentura M Agency -Charles University. Pp. C117-124.

TREMBLAY, D.-G (2004). Les communautés virtuelles de praticiens : vers de nouveaux modes d'apprentissage et de création de connaissances ? Possibles, numéro spécial sur la formation. septembre 2004.

TREMBLAY, D.-G (2004c). "Informal Learning Communities in the Knowledge Economy ; "Knowing Whom" As a Source of Knowledge Development in Multimedia Sector" in D. Passey ; M. Kendall (dir.). Tele-Learning : The Challenge for the Third Millenium. Proceedings of the 17th World Computer Congress. Amsterdam/New York : Kluwer Academic Publisher, 2002. pp. 241-248

TREMBLAY, D.-G et ROLLAND, D. (2000). Labour regime and industrialisation in the knowledge economy; the Japanese model and its possible hybridisation in other countries. Labour and Management in Development Journal. No 7. Brisbane: The Australian National University. http://www.ncdsnet.anu.edu.au.

TREMBLAY, D.-G et ROLLAND, D. (1998). Gestion des ressources humaines; typologies et comparaisons internationales. Québec: Presses de l'université du Québec.

TREMBLAY, D.-G., ROLLAND, D. and E. DAVEL (2000). Travail en équipe, compétences et pratiques de sélection au Québec. Dans Cadin, Loïc (2000, sous la dir.). Internationalisation de la GRH ? CD rom des Actes du XI Congrès de I'Association francophone de Gestion des ressources humaines. 25 p.

WENGER, e. (1998). Communities of Practice - Learning as a social system. Systems thinker. June.

Wenger, E., R. McDermott and W. Snyder (2002). Cultivating Communities of Practice. A guide to manatging Knowledge. Boston : Harvard Business School Press.

Wenger, E. and W. Snyder (2000). Communities of Practice : The Organisational Frontier. Harvard Business Review. V.78. no0 1, pp. 139-145.

Wenger, E. and Lave (1991). Communities of practice. 